\title{
EDUCAÇÃO AMBIENTAL E CONSTRUÇÃO CIVIL: PRÁTICAS DE GESTĀO DE RESÍDUOS EM FOZ DO IGUAÇU-PR
}

\author{
Juliana Pires Frigo1, Djalma Silva da Silveira \\ ${ }^{1}$ Especialista em Educação Ambiental, Centro de Ciências Rurais, UFSM, Santa Maria-RS, Brasil I, \\ arq.julianafrigo@gmail.com \\ 2Professor do Curso de Especialização em Educação Ambiental, Centro de Ciências Rurais, UFSM, \\ Santa Maria-RS, Brasil, djalma@ufsm.br
}

\section{RESUMO}

Atualmente uma das grandes preocupações a nível mundial é com a preservação do meio ambiente, dentre estas à geração de resíduos urbanos. Os resíduos têm grande relação com a história da humanidade, pois sempre estiveram presentes no cotidiano populacional, com o constante processo de urbanização acarretou o aumento nos índices da construção civil, tais demandas por novos espaços construídos trouxeram também novos problemas ambientais para os centros urbanos como, por exemplo, o destino final ou aproveitamento adequado dos resíduos da construção civil. O estudo visa principalmente, promover a conscientização quanto à importância da educação ambiental a cerca dos resíduos gerados pela construção civil. Para tanto foram utilizados os seguintes procedimentos metodológicos: levantamento fotográfico sendo possível identificar os principais destinos dos resíduos da construção civil e, a confecção de um folheto técnico que se caracteriza como uma prática de educação dirigida ao meio ambiente, sendo dialética e aplicada combinando elementos científicos e teóricos, resultando na aplicação e explanação do assunto através do folheto em quinze obras na cidade de Foz do Iguaçu-PR, obtendo êxito em sua aplicação, por possuir uma linguagem adequada, de fácil entendimento no que se refere às questões ambientais, possibilitando total compreensão por parte dos profissionais e população em geral. Esta prática como forma de educação tem papel fundamental, pois é possível contribuir com a sensibilização dos indivíduos e na transformação de suas práticas cotidianas, destacando que tais informações não podem ser passadas como simplesmente transferência de conhecimento é necessário que se estabeleça um diálogo, uma comunicação.

Palavras-chave: Meio Ambiente; Resíduos; Conscientização;

\section{ABSTRACT}

Nowadays, one of the biggest worries in a world level is about to preserve the environment, among them, the urban waste production. The wastes have a great relationship with the human history, because they were always present in the daily people lives, so with the constant urbanization process it led the civil building indexes growth, such demands for new building spaces brought also new environmental problems to the urban centers such as, for example, the final destination of the civil buildings wastes or even their proper uses. The present study aims mainly purpose to promote the awareness of the environmental education importance about the wastes produced by the civil building. For this, it was used the following methodological procedures: photographic survey where it was possible to identify the mainly civil building wastes destinations and, the technical leaflet making that characterizes an education practice related to the 
environment, being dialectic and applied that combine scientific and theoretical, resulting in the application and explanation of the subject through the brochure fifteen works in the city of Foz do Iguaçu, PR, succeeding in its application, being showed to an adequate language and with an easy comprehension in the aspects that refer to the environmental questions, enabling a total comprehension by the professionals and the general population. This practice as an education form has a fundamental role, because it's possible to contribute to the individual's sensitization as well as in the everyday practices transformation, emphasizing that these information can't be passed away as a simple knowledge transference, it is necessary to establish a dialogue, a communication.

Keywords: Environment; Wastes; Awareness;

\section{INTRODUÇÃO}

Antigamente a preservação ambiental, era vista pela sociedade como uma questão defendida apenas por ecologistas radicais que se preocupavam apenas com a preservação do meio ambiente sem considerar o desenvolvimento como um todo. Diante deste contexto, o assunto era tido como uma barreira ao progresso e ao desenvolvimento econômico do país.

No Brasil o crescimento, dos contingentes populacionais nas cidades, a grande diversificação de atividades industriais e o aumento no consumo de bens e serviços têm se dirigido para uma situação alarmante se tratando do consumo crescente e descontrolado de recursos naturais.

O homem diferencia-se dos demais seres vivos por suas inúmeras capacidades, entre elas o de produzir e transformar continuamente suas técnicas através do aperfeiçoamento e estudo contínuo dos resultados, os quais fazem parte deste conjunto os materiais utilizados e a forma como são empregados. A construção civil desde os primórdios apareceu para atender as necessidades básicas e imediatas do homem sem preocupação com a técnica aprimorada em um primeiro momento.

O setor da construção civil é conhecido como um dos grandes responsáveis pelos impactos ambientais. Estes começam pela grande quantidade de recursos naturais e energias utilizadas na produção e transporte de matérias primas, passam pela concepção do projeto e terminam em um grande volume de resíduos resultantes de técnicas de construção muitas vezes artesanais, empregadas por uma mão-de-obra desqualificada.

A crescente geração de resíduos sólidos resultantes de construções, demolições e reformas na construção civil vêm exigindo cada vez mais soluções diversificadas de forma a diminuir o excedente de materiais descartados e encaminhados para os aterros sanitários bem como potencializá-los o uso dos mesmos na geração de matérias-primas secundárias, visando diminuir a exploração dos recursos naturais não-renováveis de maneira que contribuam nas condições ambientais dos espaços urbanos.

Não bastasse a degradação ambiental, o descarte clandestino e o desperdício desses resíduos acabam por ocasionar a perda da qualidade ambiental dos espaços urbanos e, consequentemente gerar grandes custos aos gestores públicos.

É cada vez mais claro que existem problemas que necessitam de solução urgente, principalmente no meio ambiente urbano. Entre estes, está à questão do gerenciamento dos 
resíduos sólidos urbanos gerados nos vários processos de produção e consumo como, por exemplo, resíduos da construção civil.

A preservação ambiental é uma preocupação no mundo todo. Através de séculos vem-se conquistando por parte da humanidade espaços que aparecem quase que em sua totalidade em detrimento de uma continua e crescente busca de novas tecnologias bem como pressão sobre recursos naturais.

A construção civil não é diferente, apesar de apresentar inúmeros benefícios socioeconômicos para o país, como alta geração de empregos, renda, moradias, infra-estrutura, entre outros, ainda apresenta alguns problemas, como a destinação de seus resíduos, principalmente nos centros urbanos.

O conhecimento de temas como a redução de resíduos, a correção no sistema de coleta e de disposição final, a reutilização e a reciclagem para a produção de novos materiais, ainda se apresentam bastante vagos, sendo necessário serem encarados desde os primeiros passos ate a formação superior.

Os profissionais que atuam de maneira direta ou indireta no setor construtivo, vêm tratando a questão ambiental com certo descaso. Muitos não têm sequer uma opinião formada a respeito do assunto, demonstrando total desinteresse.

Para que este pensamento se modifique é necessário primeiramente um processo de alteração cultural, considerando a educação ambiental como base para um pensamento critico em qualquer tempo ou lugar, seja de modo formal, não formal ou informal, onde promova a transformação e a construção de uma sociedade mais consciente.

Desta forma a educação contribui para a sensibilização de um indivíduo, a fim da transformação de suas práticas, onde a informação tem um papel fundamental. Porém cabe destacar que essas informações não podem ser passadas como simplesmente transferência de conhecimento é necessário que se estabeleça um diálogo, uma comunicação.

Neste contexto a presente monografia tem como objetivo promover a conscientização de profissionais e população em geral, quanto à importância da educação ambiental a cerca dos resíduos gerados pela construção civil através de um folheto técnico.

\section{MATERIAIS E MÉTODOS}

A pesquisa caracteriza-se como exploratória e explicativa, apresentando uma abordagem qualitativa. Com isso permitiu o conhecimento sobre os resíduos gerados pela construção civil e seus impactos no meio ambiente.

Através de uma pesquisa de campo foi possível conhecer os principais destinos dos resíduos gerados pela construção civil na cidade de Foz do Iguaçu/PR. Também possibilitou uma conversação informal com alguns profissionais da área visando apresentar a eles aspectos relacionados à construção civil e meio ambiente, e através deste conhecimento analisar qual o interesse dos mesmos quanto à preservação do Meio Ambiente.

$O$ estudo foi realizado em quatro etapas:

10 Coleta de dados - A coleta de dados foi de suma importância para o conhecimento dos principais locais de descarte dos resíduos da construção civil de Foz do Iguaçu. Esta se realizou através de uma pesquisa documental e levantamento fotográfico nos principais locais de descarte indicado por profissionais atuantes desta área (engenheiros, arquitetos, pedreiros, etc.) 
20 Análise dos dados coletados- A partir da pesquisa documental na Prefeitura Municipal de Foz do Iguaçu (PMFI), foi possível identificar o local de descarte adequado dos resíduos urbanos (aterro sanitário). Com o levantamento fotográfico observou-se em diferentes áreas da cidade locais de destinos dos resíduos da construção civil.

30 Confecção de um folheto técnico (comunicação aplicada)- Com posse dos dados foi desenvolvido e confeccionado um folheto técnico de conscientização destinada aos profissionais da área da construção civil e comunidade em geral, ressaltando a importância de um uso ou reuso adequado dos resíduos gerados. O folheto também aborda a respeito da forma e do destino adequado para os resíduos da construção civil que não sejam possíveis o uso ou reuso. Este se caracteriza como uma prática de educação dirigida ao meio ambiente, sendo dialética e participativa que combina elementos científicos e teóricos com a sua aplicação.

4 Aplicação do folheto técnico - Para aplicação do folheto foram escolhidas 15 obras, totalizando um numero de 60 profissionais, sendo estes ( técnicos responsáveis, pedreiros e comunidade).

\section{RESULTADOS E DISCUSSĀO}

Localizada no extremo oeste do Paraná, Foz do Iguaçu faz divisa com Paraguai e Argentina, como mostra a Figura 1. Sua economia está fortemente vinculada ao turismo, no entanto de acordo com o Jornal Gazeta do Povo, após uma década de estagnação a construção civil da cidade vive um momento de crescimento, isto devido ao desenvolvimento de um pólo universitário, os que a exemplo dos ciclos de Itaipu, dos sacoleiros e do turismo, tendem a gerar efeitos positivos em cadeia para a cidade.



Figura 1. Mapa do Brasil com destaque para a localização da cidade de Foz do Iguaçu/PR Fonte: Site Itaipu (2011) 
Aquecido o mercado imobiliário, responde hoje por algo entre $25 \%$ e $30 \%$ da movimentação de dinheiro na cidade, garante Jilson José Pereira, vice-presidente do Sindicato de Habitação e Condomínios do Paraná (Secovi-PR). Boa parte destes investimentos são reflexos da procura por segurança em condomínios horizontais e verticais.

Esta crescente demanda da construção civil na cidade traz reflexos positivos do ponto de vista econômico, no entanto trazem junto reflexos negativos principalmente em relação à gestão deste crescente mercado.

Um dos principais pontos negativos do crescimento acelerado da construção civil de uma cidade á a alta geração de resíduos produzidos pelo setor. Mais preocupante ainda do que a alta geração dos resíduos é o seu adequado destino final.

As pesquisas bibliográficas juntamente com a pesquisa de campo possibilitaram a identificação dos principais destinos para os resíduos da construção civil de Foz do Iguaçu-PR. Com o estudo foi possível identificar claramente dois tipos de destinos finais destes materiais, sendo eles: Aterro sanitário e varias áreas ociosas da cidade.

\section{Destino 1 - Aterro Sanitário de Foz do Iguaçu-PR}

De acordo com dados fornecidos pela Prefeitura Municipal de Foz do Iguaçu-PR, até o ano de 2001 o município não contava com nenhum aterro sanitário, sendo utilizado somente os lixões, que conforme a SMMA( Secretaria Municipal do Meio Ambiente), caracteriza-se pela inexistência de proteção ao meio ambiente. Tornando-se preocupantes na época, pois se localizavam próximo à estrada das Cataratas, dentro do manancial de captação de águas da cidade, aumentando enormemente os riscos de contaminação do lençol freático, associados a outros, tais como poluição atmosférica por gases e vapores de fumaça, danos à saúde pública por contato direto com o lixo por parte de catadores, ou indireto, devido a vetores de doenças, conforme mostra a Figura 2.

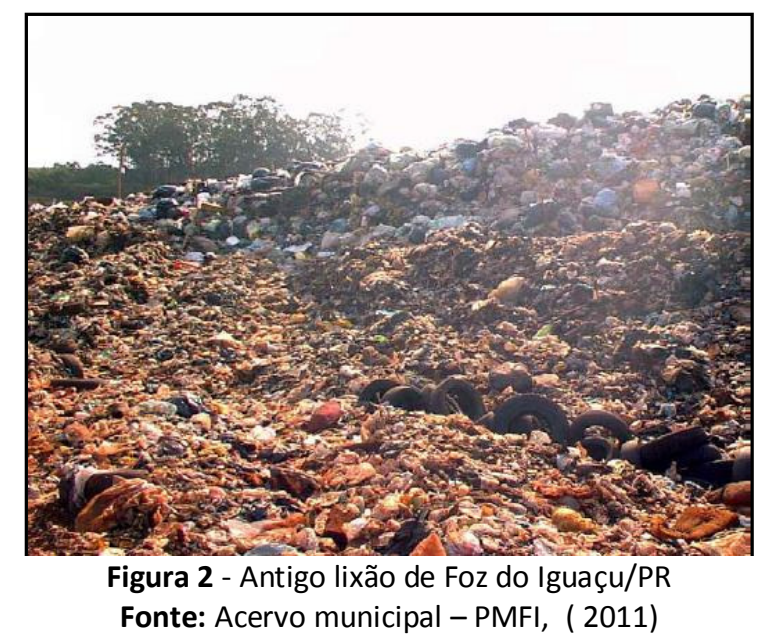

A partir de 2001 o município de Foz do Iguaçu conta com um local adequado para o destino dos resíduos urbanos, aterro sanitário que possui área de aproximadamente $570.354,00 \mathrm{~m}^{2}$, Figura 3. 


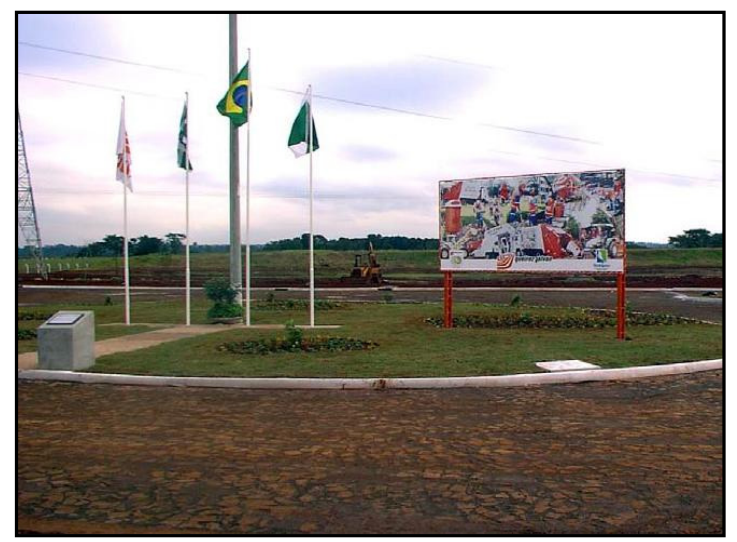

Figura 3 - Aterro sanitário de Foz do Iguaçu/PR Fonte: Acervo municipal - PMFI, (2011)

O aterro sanitário está localizado na Rua Ângelo Aparecido de Andrade noroeste do município, entre os bairros Porto Belo e Jardim Califórnia. $\mathrm{O}$ acesso à área se faz a partir do $\mathrm{Km} 45$ da Rodovia Tancredo Neves, sentido centro/Itaipu Binacional, seguindo a rua Vicinal Ângela Aparecida de Andrade, Figura 4.

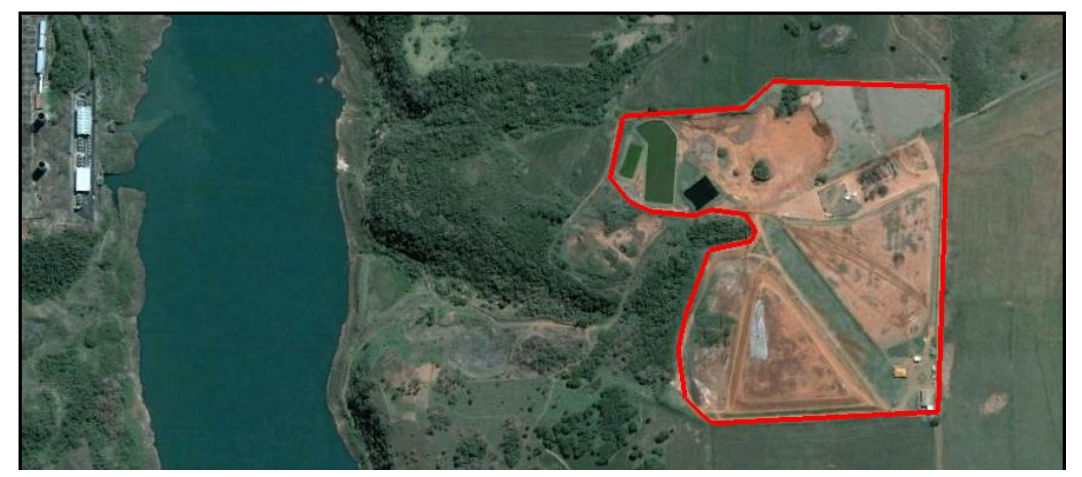

Figura 4 - Imagem aérea da área destinada ao Aterro de Foz do Iguaçu/PR Fonte: Google Earth (2011), adaptada pela autora.

A partir de uma breve análise da localização do aterro sanitário de Foz do Iguaçu, pode-se afirmar que se encontra em uma área de fácil acesso para que ocorra o descarte dos resíduos, no entanto é possível observar que sua localização é bastante preocupante do ponto de vista ambiental, devido a sua proximidade a um dos maiores e mais importantes rios do Brasil, o Rio Paraná.

O aterro sanitário da cidade possui duas áreas específicas uma para resíduos da construção civil e outra para resíduos domiciliares conforme mostra a Figura 5. 


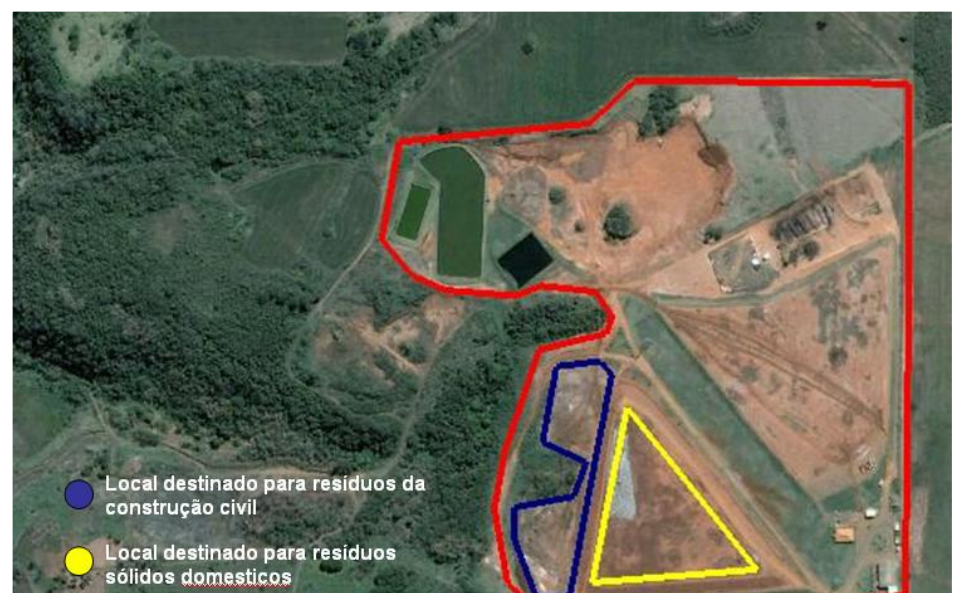

Figura 5 - Imagem aérea do zoneamento do aterro sanitário de Foz do Iguaçu/PR Fonte: Google Earth (2011), adaptada pela autora.

A separação dos resíduos da construção civil é de extrema importância, em se tratando de resíduos que levam muitos anos para se decompor ou até mesmo nunca chegar à decomposição.

\section{Destino - Áreas ociosas de Foz do Iguaçu - PR}

A construção civil apresenta um significativo percentual dos resíduos produzidos nas áreas urbanas, de acordo com Lima (2009) 59\% dos resíduos da construção civil são gerados por reformas, $21 \%$ por prédios novos e $20 \%$ por residências novas, assim como mostra na Figura 6.

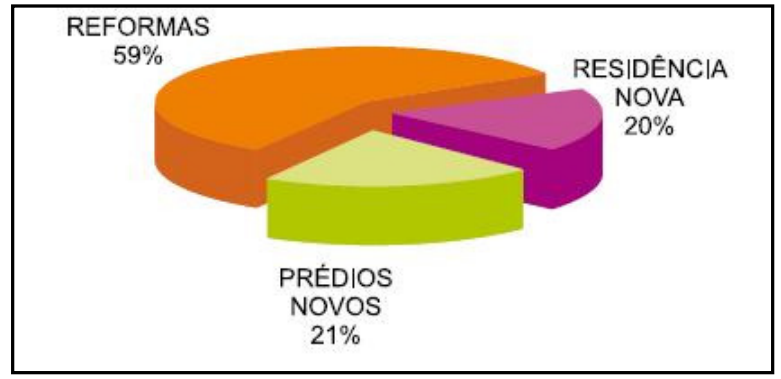

Figura 6 - Origem dos resíduos Fonte:Lima (2009)

Devendo ser considerado que os resíduos são prejudiciais ao meio ambiente, estando diretamente ligados ao esgotamento prematuro das áreas de destino final, degradação de mananciais, impedimento da drenagem urbana, sujeira nas vias públicas, compactação do solo, proliferação de vetores (insetos e roedores) e, ainda contaminação do lençol freático causado por aterros construídos com resíduos inadequados da construção civil.

Verifica-se que a autoconstrução e as pequenas reformas realizadas por pequenos empreiteiros são responsáveis por boa parte dos resíduos da construção civil, que embora em pequenos volumes e em sua maioria são transportadas de forma inadequada acabam por ser descartados em locais impróprios, causando desconforto à sociedade em torno de suas casas, uma vez que estes locais tornam-se atrativos para descarte de outros resíduos como pneus, móveis, resíduos domésticos, animais mortos dentre outros. 
A partir de levantamentos realizados em diferentes áreas da cidade de Foz do Iguaçu, foi possível identificar muitas áreas que recebem inadequadamente os resíduos da construção civil como destino final, devido estar localizadas em áreas ociosas e mais afastadas da circulação da maioria da população.

As figuras 07 e 08 mostram os resíduos encontrados em um terreno ocioso, estes foram ali depositados sem separação adequada, onde é possível observar diferentes tipos de resíduos.

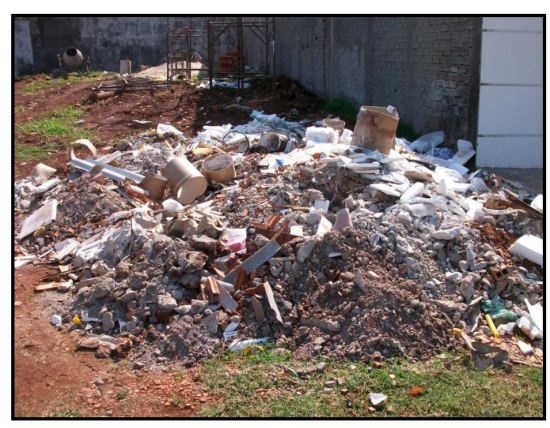

Figura 07 - Local dos resíduos 1-a Fonte: Frigo (2011)

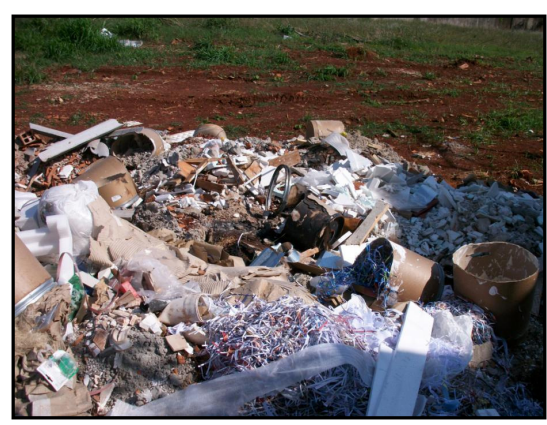

Figura 08 - Local dos resíduos 1-b Fonte: Frigo (2011)

As figuras 09 e 10 mostram diversas áreas onde estão depositados parte dos resíduos das construções da cidade, bem como as figuras 11, 12, 13, 14 apresentam e mesmo desfecho sejam estes resíduos de construções novas, reformas e até mesmo pela troca de equipamentos de infraestrutura urbana (poste de iluminação pública).

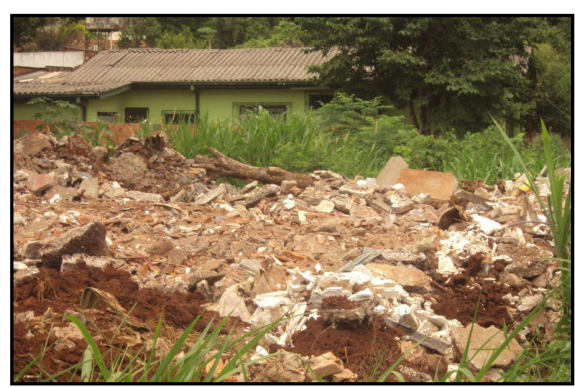

Figura 09 - Local dos resíduos 2-a Fonte: Frigo (2011)

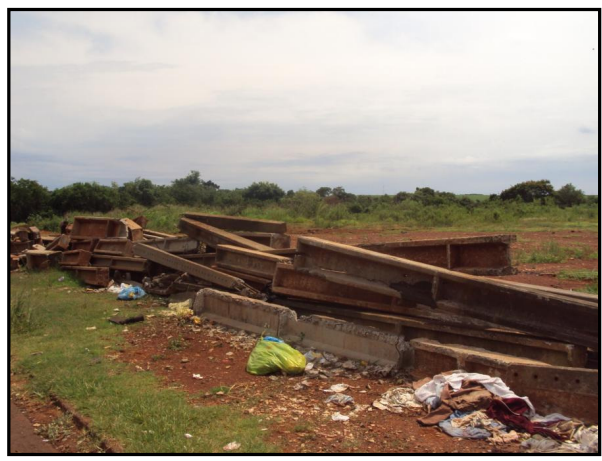

Figura 11 - Local de destido dos resíduos 3-a Fonte: Frigo (2011)

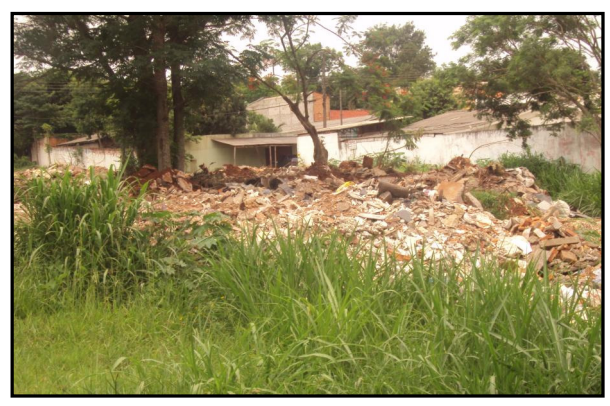

Figura 10 - Local dos resíduos 2-b Fonte: Frigo (2011)

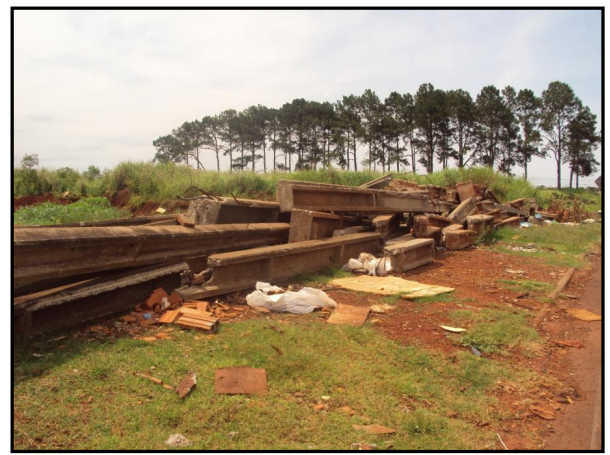

Figura 12 - Local dos resíduos 3-b Fonte: Frigo (2011) 


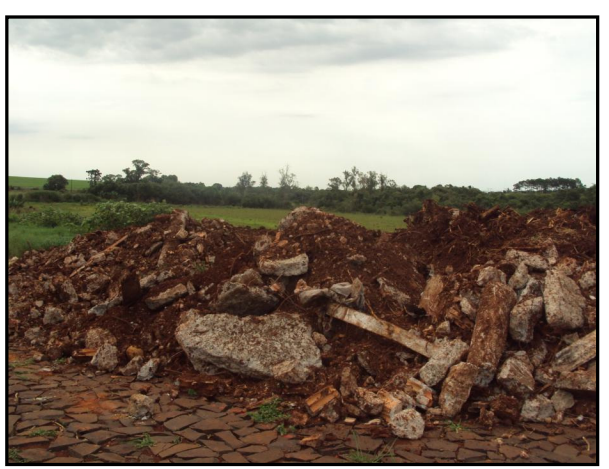

Figura 13 - Local de destino dos resíduos 4-a Fonte: Frigo (2011)

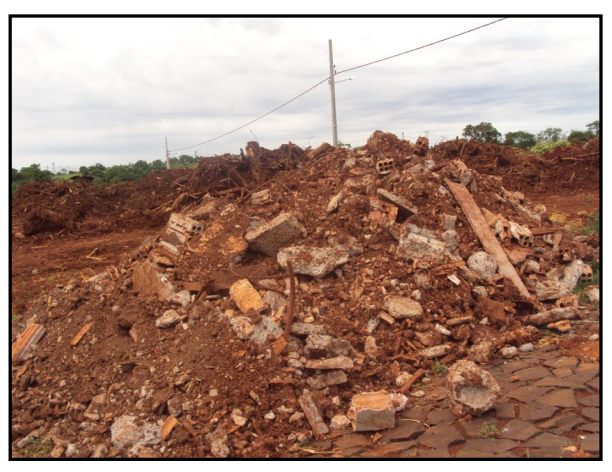

Figura 14 - Local dos resíduos 4-b Fonte: Frigo (2011)

\section{Confecção de um folheto técnico}

A partir da coleta dos dados, foi possível desenvolver um folheto técnico que dispõe de uma linguagem adequada e de fácil entendimento no que se refere ao assunto, possibilitando uma total compreensão por parte dos profissionais e população em geral.

Questões presentes no Folheto Técnico

As questões inseridas no folheto técnico seguem abaixo.

- Educação ambiental;

- Resíduos;

- Origem dos resíduos na construção civil;

- Como reduzir os impactos dos resíduos no Meio Ambiente;

- Desperdício da construção civil;

- Reciclagem dos Resíduos da construção civil;

- Como evitar o desperdício na construção civil;

\section{Comunicação aplicada (folheto)}

Segundo Jacobi (2004), a informação ocupa um lugar de destaque, afirmando que a educação sensibiliza as pessoas transformando suas ações na defesa da qualidade de vida.

Para Higuchi e Azevedo (2004) é essencial compreender como as pessoas pensam, aprendem e agem no meio em que vivem, pois a prática da educação ambiental depende da concepção de cada indivíduo sobre o meio ambiente.

A educação não é apenas transferência de conhecimento e sim co-participação no ato de compreender. A linguagem técnica deve ser adaptada a realidade de cada local a se trabalhar (FREIRE, 1986).

Os folhetos foram aplicados em 15 (quinze) obras residenciais na cidade de Foz do Iguaçu$\mathrm{PR}$, estas obras foram selecionadas a partir do contato de alguns profissionais (engenheiros, arquitetos, construtoras), bem como algumas pessoas da comunidade. Destas 15 (quinze) obras, 10 (dez) apresentavam-se em diferentes etapas de execução de obras novas tendo profissionais 
técnicos responsáveis, e, as 5 (cinco) demais em etapa de reformas, as quais não apresentavam profissionais técnico responsáveis.

Em cada uma das obras foi realizada a explanação do assunto presente no folheto, bem como a entrega dos mesmos para os profissionais da área da construção civil e também para comunidade.

Observou-se que a comunicação estabelecida com os profissionais da área da construção civil e população foram de fundamental importância para a elaboração do folheto técnico que, pelo seu formato de linguagem acessível, obteve a compreensão e sensibilização dos mesmos.

Os profissionais destacaram que realmente não tinham consciência de como os resíduos podem ser prejudiciais ao meio ambiente, e demonstraram grande interesse de mudança, tanto na disseminação do conhecimento que o folheto proporcionou a eles, como na preocupação em relação à utilização de baias para realização da separação dos mesmos.

Para o total sucesso do trabalho é importante que se estabeleça uma parceria com órgãos publico e privados para confecção do folheto em grande escala, para que sua aplicação não fique restrita somente nas 15 obras que fizeram parte do presente trabalho, com isso será possível ampliar os conhecimentos a cerca da preservação ambiental com foco da reciclagem e destinação correta dos resíduos gerados pela construção civil.

\section{CONCLUSÕES}

Com a realização do presente estudo, foi possível detectar dois principais pontos de descarte dos resíduos da construção civil no município de Foz do Iguaçu.

$\mathrm{O}$ aterro sanitário, local adequado para o destino de resíduos urbanos, que foi construído no ano de 2011, possui extensa área, conta com um local destinado separadamente para os resíduos da construção civil, sendo considerado de fundamental importância, pois estes resíduos levam anos para se decompor. Ressaltando sua localização em uma área de fácil acesso para o descarte, contudo observa-se a preocupação do ponto de vista ambiental, estando muito próximo a um dos maiores e mais importantes rios do país, o Rio Paraná.

Outro destino são as diferentes áreas da cidade, onde recebem inadequadamente os resíduos da construção civil como destino final, devido estar localizadas em áreas ociosas e mais afastadas da circulação da maioria da população, causando desconforto para da população que vive próximo a estes lugares, bem como os problemas ambientas, uma vez que estes locais tornam-se atrativos para descarte de outros resíduos.

Estes resultados possibilitaram a confecção de um folheto técnico que foram aplicados em 15 (quinze) obras na cidade de Foz do Iguaçu-PR onde obteve êxito em sua aplicação, por possuir uma linguagem compreensível, bem como, de fácil manuseio, tanto para os profissionais da área da construção civil, quanto para comunidade em geral, podendo ser considerado como uma prática dialética e aplicada de educação. Sendo uma das maneiras mais eficazes de sensibilizar um indivíduo, a educação contribui para a transformação de suas práticas, onde a informação tem papel fundamental. No entanto essas informações não devem ser passadas como simplesmente transferência de conhecimento é necessário que se estabeleça um diálogo, uma comunicação, onde possa auxiliá-los no desenvolvimento e capacidade físicas e espirituais do individuo bem como para prepará-los para uma possivel participação ativa e transformadora de supostos obstáculos que possam aparecer diante das várias instâncias de sua vida social. Assim a comunicação estabelecida deve ser co-participativa, pois é primordial na relação humana. 
Contudo destaca-se que a obtenção de resultados concretos, deve-se a não realização de práticas que degradem o meio ambiente e afetem a saúde humana, e esta realização só será conquistada se houver uma preocupação com o processo a curto médio e longo prazo, tendo vista que há necessidade de uma mudança de conceitos, cultura e de valores, pois a educação é um processo contínuo.

Diante destes fatos verifica-se que a melhor solução para que estes problemas sejam solucionados na atualidade torna-se necessário, boas práticas de gestão dos resíduos através de normalizações, que exerçam força neste sentido, permitindo que sejam aplicadas penalidades pelo descumprimento das mesmas, havendo multas, embargo/interdição, apreensão de veículos e equipamentos que estejam no exercício da atividade.

O ponto essencial desta discussão que ainda caminha a passos curtos e lentos, a conscientização ambiental, tanto do setor publico, iniciativa privada quanto sociedade civil, é necessário para que se atinja o desenvolvimento sustentável das cidades e populações.

\section{REFERÊNCIAS BIBLIOGRÁFICAS}

ASSOCIAÇAO BRASILEIRA DE NORMAS TECNICAS (ABNT). NBR 10004 - Resíduos Sólidos - Classificação. Rio de Janeiro: ABNT, 2004.

ANGULO, S.C. ZORDAN, S.E., JOHN V. M. Variabilidade de agregados graúdos de resíduos de construção e demolição reciclados. São Paulo, 2000. 155p. Dissertação (Mestrado) - Escola Politécnica, Universidade de São Paulo.

BARBIERI, J. C. Gestão ambiental empresarial: conceitos, modelos e instrumentos. 2a ed. São Paulo: Saraiva 2007

BRASIL. Lei 9.795, de 27 de abril de 1999. Dispõe sobre a educação ambiental, institui a Política Nacional de Educação Ambiental e dá outras providências. DOU de 28/04/99.

BRUGGER, P. Educação ou adestramento ambiental? Santa Catarina: Letras Contemporâneas, 1994, 142 p. CARVALHO, I. C. M. Movimentos sociais e políticas de meio ambiente. A educação ambiental aonde fica ? In: SORRENTINO, M.; TRAJBER, R.;BRAGA, T. Cadernos do III Fórum de educação ambiental. São Paulo: Gaia, p. 58-62, 1995.

CASTRO, R. S. de; BAETA, A. M. Autonomia intelectual: condições necessárias para o exercício da cidadania. In: LOUREIRO, C. F. B. et al. Educação ambiental: repensando o espaço da cidadania. São Paulo: Cortez, 2005. p. 99-107.

DIAS, G. F. Educação ambiental: princípios e práticas. 3 ed. São Paulo: Gaia, 1994. 400p.

ENGEOSCON. Disponível em http://www.engeocons.com.br/projetos.html. Acesso em outubro de 2011.

FREIRE, P. Pedagogia da indignação: cartas pedagógicas e outros escritos. São Paulo: UNESP. 2000. Extensão ou comunicação? 4 ed. Rio de Janeiro: Paz e terra, 1980. . e SHÖR, Ira. Medo e Ousadia: o cotidiano do professor. Rio de Janeiro: Paz e Terra, 1986. . Pedagogia da autonomia: saberes necessários à prática educativa. 6 ed. São Paulo: Paz e Terra, 1997, $165 \mathrm{p}$. . Educação e mudança. Rio de Janeiro: Paz e Terra; 2001.

GRIPPI, S. Lixo: Reciclagem e a sua historia: guia para as prefeituras brasileiras. 2o Edição. Rio de Janeiro: Interciência, 2006.

GRÜN, M. Ética e educação ambiental: a conexão necessária. Campinas, SP: Papirus, 1996, 120 p. HIGUCHI, M. I. G.; AZEVEDO, G. C. Educação como processo na construção da cidadania ambiental. Revista Brasileira de Educação Ambiental, Brasília: Rede Brasileira de Educação Ambiental, v. II, n. 0, p. 63-70, nov. 2004. 
ITAIPU BINACIONAL. Disponível em http://www.itaipu.gov.br/, acesso em agosto 2011.

JACOBI, P. Educação e meio ambiente - transformando as práticas. Revista Brasileira de Educação

Ambiental, Brasília: Rede Brasileira de Educação Ambiental, v. il, n. 0, p. 28-35, nov. 2004.

JOHN, V.M. Panorama sobre a reciclagem de resíduos na construção civil. In: SEMINÁRIO

DESENVOLVIMENTO SUSTENTÁVEL E A RECICLAGEM NA CONSTRUÇÃO CIVIL, 2., São Paulo, 1999. Anais.

São Paulo, IBRACON, 1999. p.44-55.

. A construção, o meio ambiente e a reciclagem. (EP-USP/PCC), 2005, São Paulo. Acesso em

outubro de 2011.

. Reciclagem de resíduos na construção civil - contribuição à metodologia de pesquisa e

desenvolvimento. São Paulo, 2000. 102p. Tese (livre docência) - Escola Politécnica, Universidade de São

Paulo. Acesso em outubro de 2011.

. "Desenvolvimento sustentável, construção civil, reciclagem e trabalho multidisciplinar" São

Paulo, PCC/USP. 2002. Acesso em setembro 2011.

LIMA, G. F. da C. Questão ambiental e educação: contribuições para o debate.

Ambiente e Sociedade, NEPAM/UNICAMP, Campinas, ano II, no 5, 135-153, 1999.

LIMA, R.S; LIMA, R.R.R. Guia para Elaboração de Projeto de Gerenciamento de Resíduos da Construção

Civil, 2009. Acesso em outubro de 2011.

LOUREIRO, C. F. B. Educação ambiental e movimentos sociais na construção da cidadania ecológica

planetária. In: LOUREIRO, C. F. B. et al. Educação ambiental: repensando o espaço da cidadania. São Paulo:

Cortez, 2005. p. 69-98.

. Ética e cidadania: conceitos básicos para a transversalidade em educação ambiental. In:

LOUREIRO, C. F. B.; LAYRARGUES, P. P.; CASTRO, R. S. Sociedade e meio ambiente: a educação ambiental em debate. São Paulo, Cortez, 2000.

LUFT, C.P. Minidicionario Luft: português. São Paulo: Atica, 2003.

MANO, E. B.; PACHECO, É. B. A. V.; BONELLI, C. M. C. Meio ambiente, poluição e reciclagem. São Paulo:

Edgard Blücher, 2005.

MONTEIRO, P.J.H; ZYEIBIL, V.Z. Manual de Gerenciamento Integrado de resíduos sólidos. Rio de Janeiro:

IBAM, 2001. 200 p.;

MACHADO, E. M. Pedagogia e a Pedagogia Social: educação não formal. Edição: Evelcy M. Machado e Iolanda B. C. Cortelazzo - Universidade Tuiuti do Paraná. Dezembro , 2002. Acesso em 29/07/2011.

MARTINS, J. M. Dinâmicas de uma cidade: um exemplo de projeto em educação ambiental na escola. In:

MARFAN, M. A. Congresso brasileiro de qualidade na educação: formação de professores: educação

ambiental. Brasília: MEC, SEF, v. 3, p. 34-40. 2002.

[MED] MINISTÉRIO DA EDUCAÇÃO E DO DESPORTO. Implantação da educação ambiental no Brasil.

Brasília: 1ed. 1998. 157p.

MINC, C. Ecologia e cidadania. 2 ed. São Paulo: Moderna, 2005. 152 p.

[MMA] MINISTÉRIO DO MEIO AMBIENTE. Identidades da educação ambiental brasileira. Diretoria de educação ambiental. Brasília: Ministério do Meio Ambiente, 2004. 156 p.

MONTIBELLER,G.F. O mito do desenvolvimento sustentável:Meio ambiente e custos sociais no moderno sistema produtor de mercadorias. 2 ed.rev.- Florianópolis: Ed. Da UFSC, 2004.

MORIN, E. Os sete saberes necessários à educação do futuro. São Paulo: Cortez/UNESCO; 2002.

OLIVA, J. T. A educação Ambiental no ensino formal. In: MARFAN, M. A. Congresso brasileiro de qualidade

na educação: formação de professores: educação ambiental. Brasília: MEC, SEF, v. 3, p. 41-48. 2002.

OLIVEIRA, I. A. de. Princípios pedagógicos na educação de jovens e adultos. Revista da Alfabetização

Solidária, São Paulo: Unimarco, v.4, n. 4, 2004.

OLIVEIRA, M. KI. Jovens e adultos como sujeitos de conhecimento e aprendizagem. In: Revista Brasileira de

Educação. n. 12. set., 1999.

OLIVEIRA, R. F. M. de; PAES, L. da S. Ensino de botânica associado à prática de educação ambiental

utilizando estratégias didáticas. III Congresso de pesquisa e inovação da rede norte nordeste educação

tecnológica. Fortaleza, 2008. 12 p. 
PINTO, T.de P. Gestão ambiental de resíduos da construção civil: a experiência do Sinduscon-SP/ Tracisio de Paulo Pinto, São Paulo: Obra limpa: Sinduscon-SP, 2005. Acesso em outubro de 2011.

PINTO, T.P. Metodologia para a gestão diferenciada de resíduos sólidos da construção urbana. São Paulo, 1999. 189p. Tese (Doutorado) - Escola Politécnica, Universidade de São Paulo. Acesso em setembro de 2011.

PHILIPPI, L. S. A Construção do Desenvolvimento Sustentável. In.: ARAUJO, G.C.BUENO M.P; SOUSA, A.A; MENDONÇA, P.S.M.; Sustentabilidade Empresarial: Conceito e Indicadores- III CONVIBRA - 24 a 26 de novembro de 2006. Acesso em novembro de 2011.

QUINTANA, J.M. Pedagogía Social. Madrid, Dykinson, 1988.

REIGOTA, M. O que é educação ambiental. São Paulo: Brasiliense, 1994, 62 p.

SILVA, A. L. A. Aplicação de Resíduos Sólidos da Construção Civil em Bases e Sub-bases de Pavimentos. Trabalho de Conclusão de Curso. Centro Federal de Educação Tecnológica de Goiás - CEFET-GO. 2004. Acesso em outubro de 2011.

Shanghai Yuanhua Máquinas. Disponível em http://www.crusher-mill.com/pt/Products/Hammer-

Crusher.html, acesso em outubro de 2011.

SORRENTINO, M. Universidade, formação ambiental e educação popular. In:Temas em educação. João Pessoa, PB UFPB, p. 85-89, 1995.

SPAZZIANI, M. de L. A formação de educadores ambientais para sociedades sustentáveis: memórias do processo de elaboração do projeto-piloto de um curso de especialização. Revista Brasileira de Educação Ambiental, Brasília: Rede Brasileira de Educação Ambiental, v. il, n. 0, p. 39-46, nov, 2004.

THAINES, E. Educação ambiental: abordagens em educação na prática ambientalistas das organizações não governamentais. 2006. 102 f. Dissertação (Mestrado) - Faculdade de Educação, Universidade de Passo Fundo, Passo Fundo.

TRILLA, J. La Educacion fuera de la escuela. Ambitos no formales y educación social. Barcelona. Ariel. 1996. VIOLA, E.; LEIS, H. A evolução das políticas ambientais no Brasil, 1971-1991: do bissetorialismo preservacionista para o multissetorialismo orientado para o desenvolvimento sustentável. In: HOGAN, D. J. e VIEIRA, P. F. Dilemas socioambientais e desenvolvimento sustentável. Campinas, SP: UNICAMP. p. 73-102, 1995.

ZORDAN, S. E. A Utilização do Entulho como Agregado na Confeç̧ão do Concreto. Campinas:

Departamento de Saneamento e Meio Ambiente da Faculdade de Engenharia Civil, Universidade Estadual de Campinas. Dissertação (Mestrado), 1997. 140p. Acesso em outubro de 2011. 


\section{APÊNDICES}

Apêndice (A) frente, o apêndice (B) verso, é caracterizado pelo folheto técnico desenvolvido para conscientização dos profissionais da construção civil e população em geral, quanto ao destino correto dos resíduos gerados pelo setor.

\section{APÊNDICE A - FOLHETO TÉCNICO (frente)}

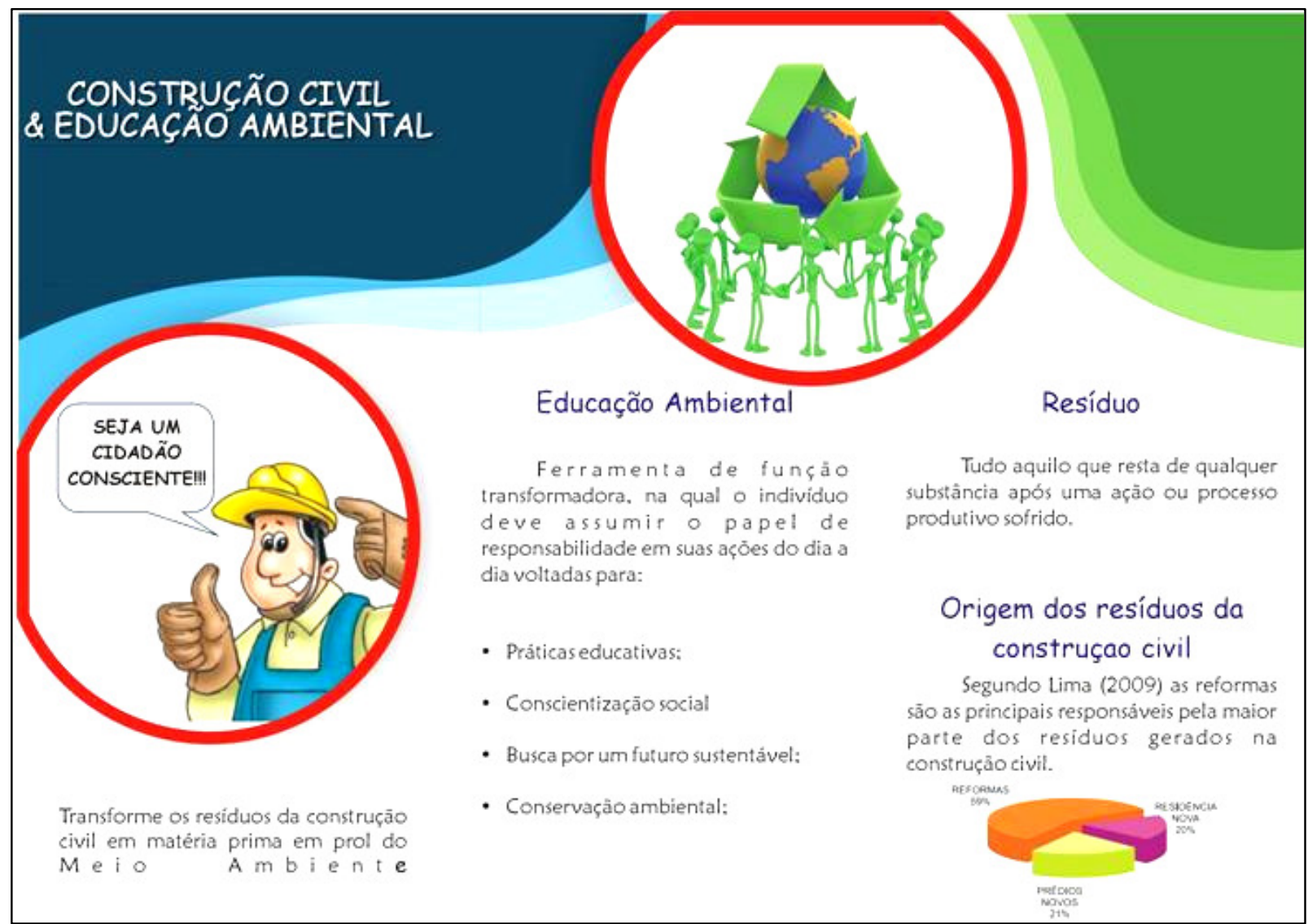




\section{APÊNDICE B - FOLHETO TÉCNICO (verso)}

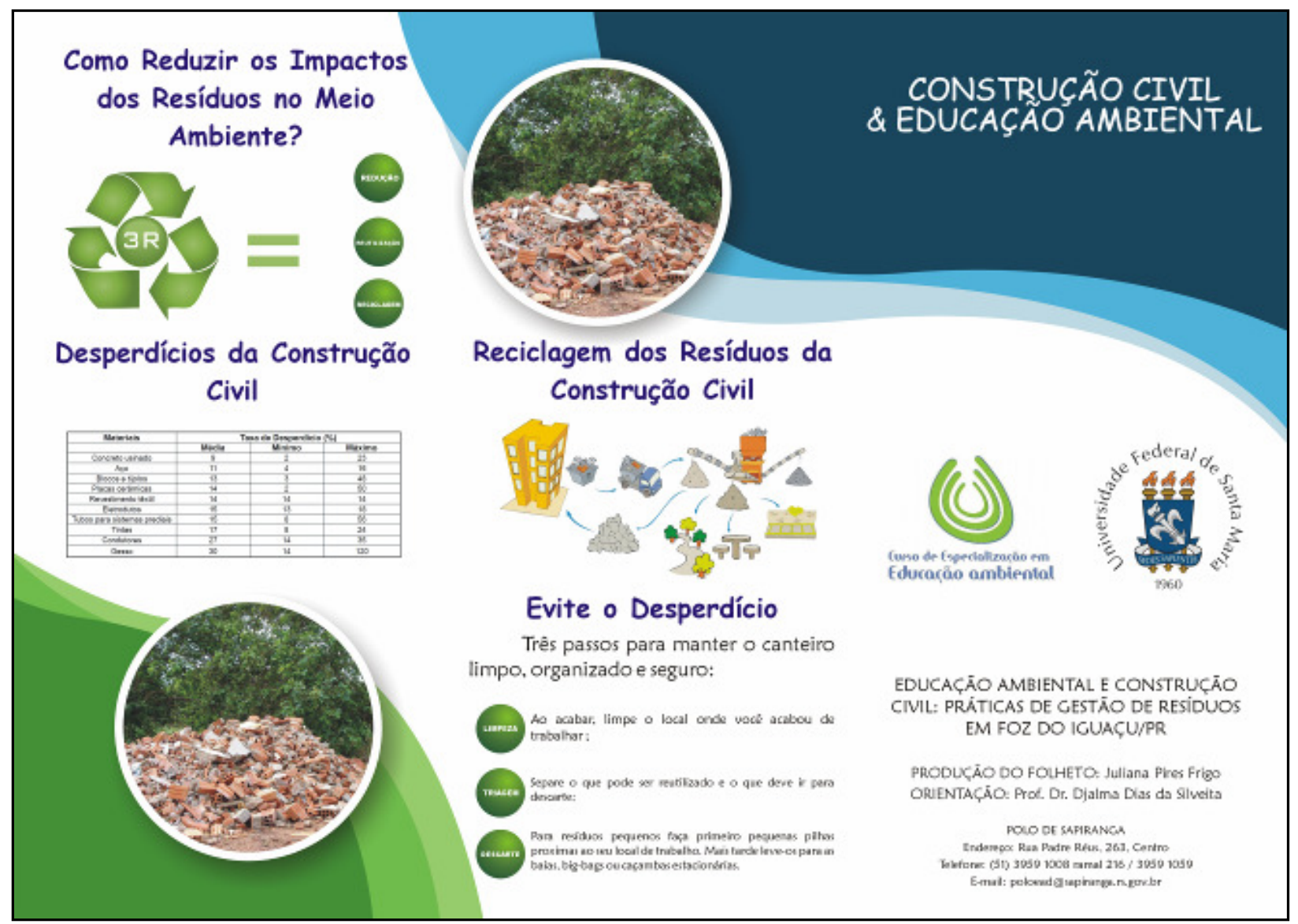

